\title{
Typical Personal Security Rights in the EU
}

Comparative Law and Economics in Italy, Spain and other EU Countries in the Light of EU Law, Basel II and the Financial Crisis

[Typische Persönliche Kreditsicherheiten in der EU. Eine rechtsvergleichende Analyse der persönlichen Kreditsicherheiten in Italien, Spanien und anderen europäischen Ländern unter besonderer Berücksichtigung von EU Recht, Basel II und den Auswirkungen]

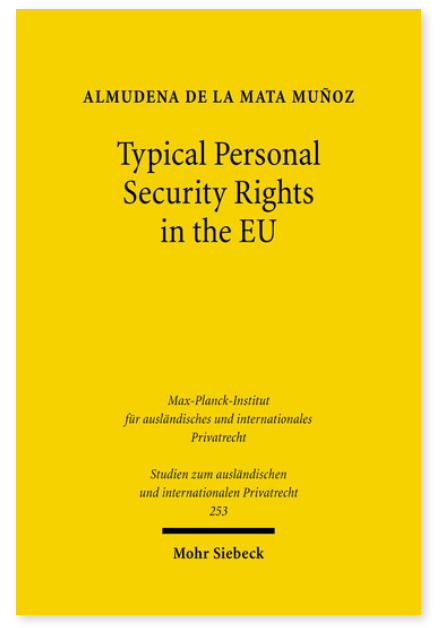

2010. XXXV, 330 Seiten. StudIPR 253

ISBN 978-3-16-151438-8

DOI 10.1628/978-3-16-151438-8

eBook PDF 79,00€

ISBN 978-3-16-150662-8

fadengeheftete Broschur 79,00€
Veröffentlicht auf Englisch.

Almudena de la Mata Muñoz bietet in ihrer rechtsvergleichenden Studie eine umfassende Analyse des Rechts der typischen persönlichen Kreditsicherheiten in der EU.

Almudena de la Mata Munoz Almudena de la Mata Muñoz: PhD (Hamburg University); Law and Business law Degrees (Uni. P. Comillas-ICADE, Madrid); Currently Legal Counsel, Spanish Central Bank, and since 2000 Lecturer, Humboldt University, Berlin, Bucerius Law School and Hamburg University.

Jetzt bestellen:

https://mohrsiebeck.com/buch/typical-personal-security-rights-in-the-eu-9783161514388?no_cache=1 order@mohrsiebeck.com

Telefon: $+49(0) 7071-923-17$

Telefax: +49 (0)7071-51104 